PRELIMINARY COMMUNICATIONS

\section{Uptake of Gallium-67 in Colonic and Rectal Tumours}

\author{
A. G. NASH, D. R. DANCE, V. R. MCCREADY, \\ J. D. GRIFFITHS
}

British Medical fournal, 1972, 3, 508-510

\section{Summary}

The uptake of ${ }^{67} \mathrm{Ga}$ in biopsy specimens of normal and abnormal tissue was measured in 20 cases of colonic and rectal disease and the ratio between the ${ }^{67} \mathrm{Ga}$ uptake in these diseases and in the normal colon or rectum was determined. Uptake of the isotope was high in most of the 14 primary malignant tumours, being highest in poorly differentiated tumours. This uptake was found to be concentrated at the active tumour edge. Uptake of the isotope was generally low in non-malignant lesions.

\section{Introduction}

Gallium-67 citrate is at present being investigated as a tumourscanning agent. Edwards and Hayes (1969) noted its concentration in a lymph node involved by a lymphoma and it has since been shown to accumulate in various neoplastic conditions (Edwards and Hayes, 1970; Winchell et al., 1970; Higasi et al., 1972). Isolated reports have shown it to be concentrated in adenocarcinomata (Lavender et al., 1971).

Existing methods of colonic investigation fail to show an appreciable number of tumours (Ramsay, 1956). It was therefore decided to investigate the uptake of ${ }^{67} \mathrm{Ga}$ in colonic and rectal tumours.

\section{Material and Methods}

Gallium-67 decays by electron capture, with a half-life of 78 hours. Its five main gamma emissions lie in the energy range 93-388 keV. For the purpose of this investigation the isotope was obtained in the form of carrier-free ${ }^{67} \mathrm{Ga}$ citrate from the M.R.C. cyclotron unit at Hammersmith Hospital. A dose of $0.5 \mathrm{mCi}$ of ${ }^{67} \mathrm{Ga}$ citrate in $5 \mathrm{ml}$ of $3.8 \%$ sodium citrate solution was administered intravenously to each patient 24 hours before operation. This gave a whole-body absorbed dose of $0.15 \mathrm{rad}$ and a dose of $1.0 \mathrm{rad}$ to bone (Edwards and Hayes, 1970).

Nineteen unselected patients who were being subjected to colonic or rectal surgery were studied, their approval first being obtained. Biopsy samples of normal and diseased colon or rectum were taken at operation, the normal tissue being taken from a region close to the diseased area. The radioactivity of the samples was counted in a 3 -in $(7 \cdot 6-\mathrm{cm})$ sodium iodide well scintillation counter and the percentage of the administered

Royal Marsden Hospital, London S.W.3

A. G. NASH, F.R.C.S., Senior Registrar in Surgery

D. R. DANCE, M.A., PH.D., Physicist

V. R. MCCREẢDY, M.SC., D.M.R.D., Consultant in Nuclear Medicine J. D. GRIFFITHS, M.S., F.R.C.S., Consultant Surgeon dose taken up per gramme of tissue was determined. The ratio of the uptake in the abnormal to that in the normal tissue was then calculated. Counting statistics of better than $3 \%$ were obtained for each sample.

In five cases a strip of tissue passing through the affected segment was examined. This strip was cut into $1-\mathrm{cm}$ sections so that the variations in uptake across it could be investigated. In all but one of those cases of carcinoma in which such a strip was not examined the tumour biopsy specimen was taken from the edge of the neoplasm.

Preoperative scanning was carried out in eight cases. These patients were given a dose of $2.0 \mathrm{mCi}$ of ${ }^{67} \mathrm{Ga}$ citrate and scans were performed 24 and 48 hours later with a Picker Magna Scanner III with a 3 -in $(7 \cdot 6-\mathrm{cm})$ crystal and a 19-hole collimator. The analyser window was set to include the $93-\mathrm{keV}$ and 184-keV gamma emissions of ${ }^{67} \mathrm{Ga}$. Throughout the scanning period the patients were receiving preoperative bowel preparation with $1 \mathrm{~g}$ of neomycin four-hourly and twice-daily bowel washouts.

\section{Results}

Twenty investigations were carried out on the 19 patients, one of whom had both a malignant and a benign lesion (Table). The uptake ratio was highest for the group of 14 primary malignant tumours, with a mean value of 4.6 and a standard deviation of $2 \cdot 4$. The value of 83 for Case 11 was caused by an abnormally low normal colon uptake and is omitted from the calculation of the mean.

The mean uptake ratios for the three cases of diverticular disease and for the two benign polyps were 1.8 and 1.3 respectively. The uptake ratio for the one case of a colonic metastasis from a primary carcinoma of the breast was $2 \cdot 5$. Cases 6 and 7 represent a rectal carcinoma and a benign polyp in the same patient, and the uptake ratios are noticeably different.

In Fig. 1 the results are grouped by disease state. There appears to be a correlation between uptake ratio and degree of tumour differentiation. The mean uptake ratios, with standard deviations, for the groups of poorly, moderately, and well differentiated tumours were $7 \cdot 9 \pm 1 \cdot 3,4 \cdot 2 \pm 1 \cdot 3$, and $2 \cdot 8 \pm 1 \cdot 6$ respectively.

An example of an activity profile constructed by serial biopsy through a colonic tumour is shown in Fig. 2. Most of the uptake was at the edge of the tumour, while in the ulcerated

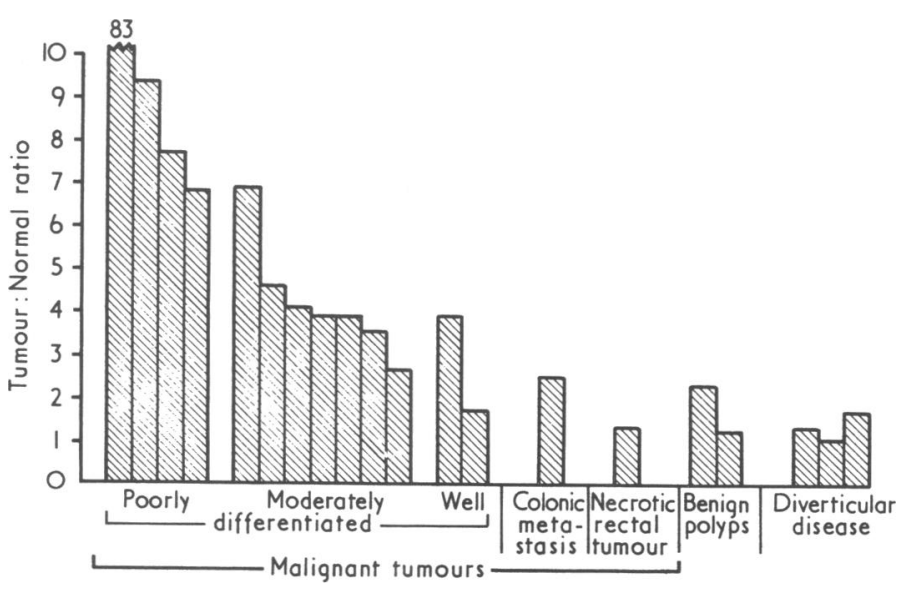

FIG. 1-Relation between disease state and ${ }^{67} \mathrm{Ga}$ uptake ratio. 


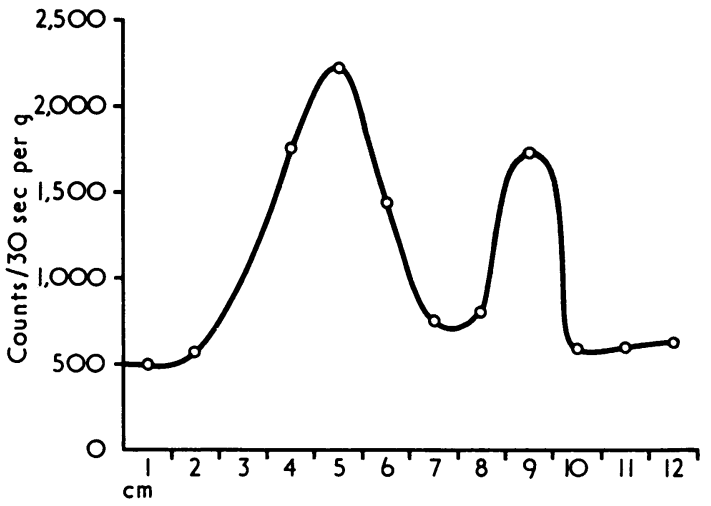

FIG. 2-Variation of ${ }^{67} \mathrm{Ga}$ uptake in transverse section of colonic tumour.

centre the uptake was similar to that of the normal colon. Similar variations were found for the other tumour profiles. In Case 9, in which the biopsy specimen was taken from the central necrotic area of an unresectable rectal carcinoma, the ratio was 1.3.

The percentage uptake of ${ }^{67} \mathrm{Ga}$ per gramme of normal colon varied between the limits of 0.00033 and 0.012 , with a mean value of 0.004 .

Uptake of ${ }^{67} \mathrm{Ga}$ in Colonic and Rectal Tumours

\begin{tabular}{|c|c|c|c|}
\hline $\begin{array}{c}\text { Case } \\
\text { No. }\end{array}$ & $\begin{array}{l}\text { Age } \\
\text { and } \\
\text { Sex }\end{array}$ & Disease & $\begin{array}{c}\text { Tumour: } \\
\text { Normal } \\
\text { Ratio }\end{array}$ \\
\hline $\begin{array}{r}1 \\
2 \\
3 \\
4 \\
5 \\
6 \\
7 \\
8 \\
9 \\
10 \\
11 \\
12 \\
13 \\
14 \\
15 \\
16 \\
17 \\
18 \\
19 \\
20\end{array}$ & $\begin{array}{ll}56 & \mathrm{M} . \\
63 & \mathrm{~F} . \\
54 & \mathrm{M} . \\
37 & \mathrm{M} . \\
68 & \mathrm{~F} . \\
52 & \mathrm{M} . \\
61 & \mathrm{M} . \\
79 & \mathrm{~F} . \\
59 & \mathrm{~F} \\
70 & \mathrm{M} . \\
57 & \mathrm{M} . \\
68 & \mathrm{~F} . \\
71 & \mathrm{~F} . \\
80 & \mathrm{~F} . \\
67 & \mathrm{M} . \\
59 & \mathrm{~F} . \\
77 & \mathrm{~F} . \\
32 & \mathrm{M} . \\
63 & \mathrm{~F} .\end{array}$ & $\begin{array}{l}\text { Rectal carcinoma moderately differentiated } \\
\text { Rectal carcinoma poorly differentiated } \\
\text { Malignant polyp } \\
\text { Rectal carcinoma poorly differentiated } \\
\text { Metastases from breast carcinoma } \\
\text { Rectal carcinoma poorly differentiated } \\
\text { Benign adenomatous polyp } \\
\text { Carcinoma caecum, moderately differentiated } \\
\text { Necrotic rectal carcinoma } \\
\text { Benign polyp } \\
\text { Rectal carcinoma poorly differentiated } \\
\text { Colonic carcinoma moderately differentiated } \\
\text { Diverticular disease } \\
\text { Rectal carcinoma moderately differentiated } \\
\text { Sigmoid carcinoma moderately differentiated } \\
\text { Divericular disease } \\
\text { Diverticular disease } \\
\text { Rectal carcinoma moderately differentiated } \\
\text { Colonic carcinoma moderately differentiated } \\
\text { Colonic carcinoma well differentiated }\end{array}$ & $\begin{array}{l}2 \cdot 7: 1 \\
6 \cdot 8: 1 \\
3 \cdot 9: 1 \\
7 \cdot 7: 1 \\
2 \cdot 5: 1 \\
9 \cdot 3: 1 \\
2 \cdot 4: 1 \\
6 \cdot 9: 1 \\
1 \cdot 3: 1 \\
1 \cdot 2: 1 \\
83 \cdot 0: 1 \\
3 \cdot 9: 1 \\
1 \cdot 3: 1 \\
3 \cdot 5: 1 \\
3 \cdot 9: 1 \\
1 \cdot 0: 1 \\
1 \cdot 6: 1 \\
4 \cdot 6: 1 \\
4 \cdot 1: 1 \\
1 \cdot 7: 1\end{array}$ \\
\hline
\end{tabular}

Gallium-67 scans were carried out on eight patients. Faecal excretion of the isotope makes bowel washouts necessary, and in two cases in which obstruction was present only faecal excretion could be shown. In two patients rectosigmoid tumours were demonstrable by scanning at $\mathbf{4 8}$ hours, the faecal isotope having been cleared by bowel washouts after the 24-hour scan. In one of these patients the scan showed the activity to extend into the right pelvic wall, and at operation the carcinoma was found to extend in this direction. In another patient areas of uptake were shown all over the abdomen. This patient was found to have a poorly differentiated carcinoma with multiple omental metastases. Two patients failed to show uptake in lesions confirmed at laparotomy. A patient with a benign colonic polyp had no demonstrable abnormal uptake, while in another a 2-cm welldifferentiated tumour in the ascending colon showed no uptake. Barium-enema examinations also failed to demonstrate the latter lesion. The uptake ratio of the tumour in this case was subsequently found to be $1 \cdot 7$.

$A^{67} \mathrm{G}$ a scan carried out on a proctocolectomy specimen from a patient with chronic ulcerative colitis showed isotope concentration in a tumour of the descending colon. (Fig 3).

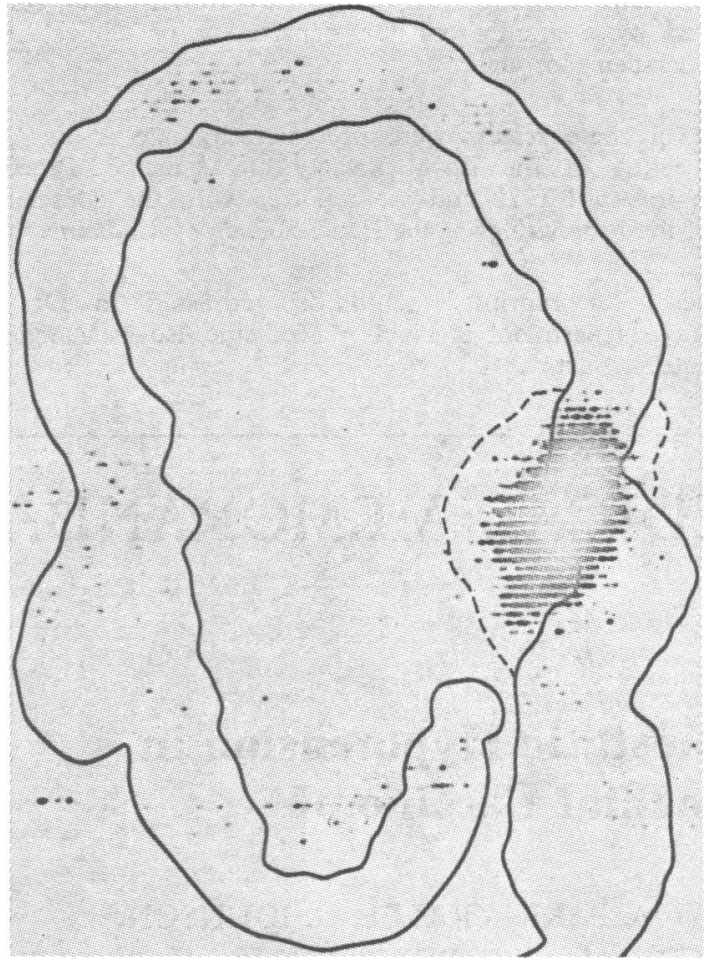

FIG. 3-Gallium-67 photoscan of colectomy specimen showing uptake in tumour.

\section{Discussion}

The mechanism of the concentration of ${ }^{67} \mathrm{Ga}$ in tumours is unknown. Recent work suggests that it is related to cellular proliferation in the tumour (Bichel and Hasen, 1972). This observation is consistent with the variations of uptake ratios present in tumours (Fig. 2) and with the relation between ${ }^{67} \mathrm{Ga}$ uptake and tumour differentiation (Fig. 1).

Since the original report of Edwards and Hayes (1969) the isotope has been extensively investigated as a tumour-scanning agent. The usual approach has been to scan a variety of tumours which happened to be available. Good concentrations were reported in the lymphomata (Kay and McCready, 1972) and in bronchial carcinoma (Ito et al., 1971).

Several authors have noted uptake of ${ }^{67} \mathrm{Ga}$ in colonic tumours (Lavender et al., 1971; Langhammer et al., 1972), but no quantitiative series of ${ }^{67} \mathrm{Ga}$ uptake in colonic conditions has previously been reported. Langhammer et al. (1972), noting a positive ${ }^{67} \mathrm{Ga}$ scan in a patient with a colonic tumour, suggested that their failure to interpret correctly the scans in other colonic neoplasms was due to the faecal excretion of the isotope. To overcome this problem they recommended a laxative to clear the colon before scanning. Colonic surgeons know that a much more thorough regimen than this is required to produce an empty bowel. Experience with the colonoscope has shown that a completely empty colon can be produced by enemas, and a lengthy stay in hospital has not proved necessary.

In view of the demonstrable accumulation of ${ }^{87} \mathrm{Ga}$ in colonic and rectal malignancy a further assessment of tumour scanning by this technique is required. In our experience the difficulties are likely to arise from the problem of completely emptying the caecum of faeces (which also makes barium studies of this organ unreliable) and from the low tumour: normal uptake ratios found in well-differentiated tumours. Gallium-67 scanning may prove to be a useful means of showing neoplastic change in patients with chronic ulcerative colitis.

We wish to thank the surgeons at the Royal Marsden Hospital for allowing us to investigate patients under their care, and Miss E. Chandler, of the isotope unit, for carrying out the clinical scans. We also wish to thank Mr. D. Vonberg and the staff of the M.R.C. 
cyclotron unit for supplying the ${ }^{67} \mathrm{Ga}$ citrate. This work was supported by a grant from the department of clinical research, Royal Marsden Hospital.

Some of these results were presented by one of us (A.G.N.) at a meeting of the Royal Society of Medicine, Proctological Section, in April 1972 and are reported with the consent of the editor of the Proceedings of the Royal Society of Medicine.

Requests for reprints should be addressed to Dr. V. $R$. McCready, Department of Nuclear Medicine, Royal Marsden Hospital, Sutton, Surrey.

\section{References}

Bichel, P., and Hasen, H. (1972). British fournal of Radiology, 45, 182. Edwards, C. L., and Hayes, R. L. (1969). Fournal of Nuclear Medicine, 10, 103.

Edwards, C. L., and Hayes, R. L. (1970). Fournal of the American Medical Association, 212, 1182.

Higasi, T., et al. (1972). Fournal of Nuclear Medicine, 13, 196.

Ito, Y., et al. (1971). Radiology, 101, 355.

Kay, D. N., and McCready, V. R. (1972). British fournal of Radiology. In press.

Langhammer, H., et al. (1972). Fournal of Nuclear Medicine, 13, 25.

Lavender, J. P., Barker, J. R., and Burn, J. I. (1971). British fournal of Radiology, 44, 361

Ramsay, G. S. (1956). British fournal of Surgery, 43, 576.

Winchell, H. S., et al. (1970). Fournal of Nuclear Medicine, 11, 459.

\section{MEDICAL MEMORANDA}

\section{Orthostatic Hypotension in Bronchial Carcinoma}

\author{
DAVID M. PARK, RALPH H. JOHNSON, \\ G. P. CREAN, J. F. ROBINSON
}

British Medical fournal, 1972, 3, 510-511

A patient with bronchial carcinoma presented with postural hypotension. Recovery of circulatory reflexes occurred after radiotherapy to the tumour.

\section{Case History}

A man of 65 years was first seen with acute retention of urine, and this recurred 12 months later. Prostatectomy was performed under general anaesthesia. During the operation he collapsed with profound hypotension, although there had been no obvious excessive blood loss. Resuscitation and recovery were uneventful. Histological examination showed simple nodular hyperplasia of the prostate gland. The chest $x$-ray picture was normal. Two months later he complained of loss of weight, intermittent constipation and diarrhoea, and faintness in relation to exertion and on standing. General and neurological examination was negative, except that the supine blood pressure of $120 / 90 \mathrm{~mm} \mathrm{Hg}$ fell to $90 / 70 \mathrm{~mm} \mathrm{Hg}$ on standing with no change in heart rate. He was admitted to hospital for further investigation. Routine blood picture, biochemistry, blood W.R., a glucose tolerance test, plasma cortisol and a rapid Synacthen test, examination of the sputum, E.C.G., barium-meal examination, and an insulin test of gastric acid secretion showed nothing abnormal. He had been a heavy smoker all his life, and a chest $x$-ray film showed a mass at the left hilum.

At thoracotomy an inoperable tumour was found, and a biopsy specimen was taken. Histologically this showed an undifferentiated carcinoma of oat-cell type, but with pleomorphism in some areas. Progress was satisfactory and treatment with fludrocortisone $(0.2 \mathrm{mg}$ daily) and the use of elastic stockings produced some symptomatic relief of his orthostatic hypotension. A course of radiotherapy was

\footnotetext{
University Department of Neurology, Institute of Neurological Sciences and Division of Medicine, Southern General Hosp.tal, Glasgow.

DAVID M. PARK, B.M., M.R.C.P., Research Fellow

RALPH H. JOHNSON, D.M., D.PHIL., Senior Lecturer and Consultant Neurologist

G. P. CREAN, PH.D., F.R.C.P., Consultant Physician

J. F. ROBINSON, M.B., M.R.C.P., Consultant Physician
}

given, and one month after its completion he still had severe orthostatic hypotension, the supine systolic blood pressure of $150 \mathrm{~mm} \mathrm{Hg}$ falling to $70 \mathrm{~mm} \mathrm{Hg}$ on standing.

Six months later he was well, gaining weight, and had no symptomatic or measurable orthostatic hypotension. A chest $x$-ray examination at that time showed some scarring in the left hilar region only. There was no evidence of recurrence two years after radiotherapy, and no supine hypertension or orthostatic hypotension was present (Fig. 1D).

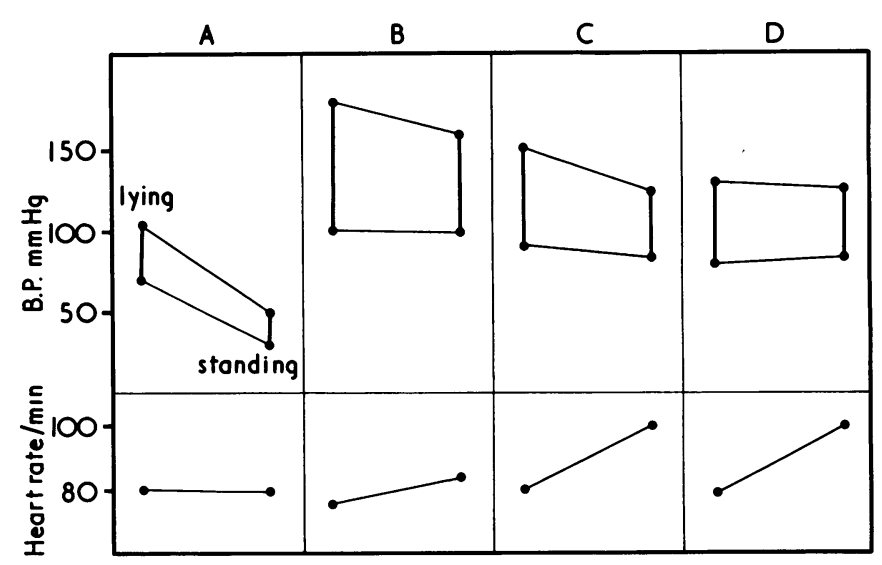

FIG 1-Blood pressure and heart rate in relation to change of posture from supine to upright. A, Severe orthostatic hypotension and no reflex tachycardia before radiotherapy. B, Moderate hypertension with slight increase of heart rate three months after radiotherapy. C. Mild postural fall of blood pressure with reflex tachycardia 15 months after radiotherapy. D, No orthostatic hypotension with rise of heart rate on change of posture 18 months after radiotherapy.

\section{AUTONOMIC FUNCTION}

In addition to the routine sphygmomanometer recording of blood pressure, circulatory reflexes were investigated before thoracotomy, after radiotherapy, and 15 months after thoracotomy by using an intraarterial catheter and a capacitance manometer and recording system (Elema-Schönander). Heart rate (beats $/ \mathrm{min}$ ) was calculated from a continuous E.C.G. record. Responses to change of posture from supine to upright on a tilting table, to a loud and unexpected noise (firing a starting-pistol), to a rapid sequence of mental arithmetic, to Valsalva's manoeuvre (Sharpey-Schafer, 1955), and to infusion of noradrenaline (Levophed) were assessed. Thermoregulatory sweating was assessed by using 1, 4-dihydroxyanthraquinone (Quinazarin) powder, and the integrity of postganglionic sudomotor fibres was assessed by iontophoresis of acetylcholine (Macmillan and Spalding, 1969).

When subjected to tilting before thoracotomy the heart rate was 81./min and remained unchanged in spite of a fall of blood pressure from $105 / 70$ to $50 / 30 \mathrm{~mm} \mathrm{Hg}$ when the ratient's position was changed from supine to upright (Fig. 1A). After return to the supine position 